\title{
Effect of extended training on generalization of latent inhibition: An instance of perceptual learning
}

\author{
Gabriel Rodríguez • Gumersinda Alonso
}

Published online: 5 February 2011

(C) Psychonomic Society, Inc. 2011

\begin{abstract}
Four experiments examined generalization of latent inhibition (LI) as a function of the length of preexposure in a conditioned taste aversion procedure with rats. Experiment 1 showed that one or four nonreinforced presentations of a flavor compound (BX) retarded subsequent conditioning to another compound (AX). However, after eight presentations of $\mathrm{BX}$, conditioning to $\mathrm{AX}$ occurred at the same rate as with no preexposure. These results indicate that generalization of LI decreased as the length of preexposure to BX increased. Experiment 2 replicated this effect of reducing generalization, as well as demonstrating that LI actually increased as the length of preexposure to $\mathrm{AX}$ increased. Experiment 3 extended the generality of the effect to a procedure in which both BX and AX were preexposed. Experiment 4 demonstrated a similar reducing-generalization effect when generalization of LI from BX to X was assessed. All of these data are consistent with the notion that prolonged preexposure to BX enhances its discriminability. Different learning mechanisms that might be responsible for this perceptual learning effect are discussed.
\end{abstract}

Keywords Stimulus preexposure - Generalization · Latent inhibition · Flavor aversion

Nonreinforced preexposure to a stimulus reduces both its ability to evoke its unconditioned response (UR) and the ease with which it becomes established as a conditioned stimulus (CS) when it is subsequently paired with an unconditioned stimulus (US). These two phenomena,

G. Rodríguez $(\bowtie) \cdot G$. Alonso

Facultad de Psicología, Universidad del País Vasco,

Avenida de Tolosa 70,

20018 San Sebastián, Spain

e-mail: gabriel.rodriguez@ehu.es known, respectively, as habituation and latent inhibition, are not the only consequences of stimulus preexposure. The ease with which a stimulus is discriminated from other similar stimuli can also be enhanced (i.e., the generalization between them can be reduced) by appropriate nonreinforced experience with that stimulus. The latter phenomenon is called perceptual learning (see Hall, 1991, for a review of the three phenomena).

Perhaps one of the simplest pieces of evidence for perceptual learning comes from studies assessing the effect of extended habituation training on generalization. In these experiments, separate groups initially receive a different number of nonreinforced presentations of a specific stimulus A. Over the course of this training, it is observed that this stimulus initially evokes a particular UR and that the likelihood of this response later declines (i.e., habituation occurs). During a subsequent test phase, it is observed that an increase in the amount of training leads to a reduction in the readiness with which the loss of responsiveness to stimulus $\mathrm{A}$ (i.e., the habituation to this stimulus) is generalized to a new stimulus B (e.g., Gillette \& Bellingham, 1981; Smith \& Council, 1978; Stephenson \& Siddle, 1976; Waters \& MacDonald, 1974). In other words, discrimination between the test stimulus B and the (rather similar) training stimulus A occurs more readily when the stimulus A has been rendered fully familiar. This outcome has been taken as showing that repeated nonreinforced experience with a stimulus changes the way in which this stimulus is perceived.

To put this interpretation in more formal terms, consider first the standard explanation for the phenomenon of generalization (e.g., Mackintosh, 1974; Rescorla, 1976). This relies on the assumption that stimuli are multifaceted and made up of many features or elements. For example, A and $\mathrm{B}$ can be thought of as compound stimuli, $a x$ and $b x$, where $x$ represents those features that are common to both, 
and $a$ and $b$ represent those that are unique to $\mathrm{A}$ and $\mathrm{B}$, respectively. Generalization of habituation between $A$ and $\mathrm{B}$ will occur automatically, first, to the extent that A and B have features in common (i.e., the proportion of $x$ elements), and second, to the extent that preexposure to stimulus A was effective in endowing habituation to these common elements. Extended training with stimulus A can be expected to establish more firmly habituation to all of its elements, both type $a$ and $x$. Therefore, if no other processes are operating, generalization to $\mathrm{B}$ should be more marked than that obtained when less habituation training is given with $\mathrm{A}$. The fact that the aforementioned studies found just the opposite result prompts the following speculation: Prolonged nonreinforced presentations of stimulus A, besides increasing the habituation to the $a$ and $x$ elements, must also reduce in some way the proportion of the $x$ elements that are effectively perceived (the nature of the perceptual learning mechanism for this reduction will be taken up in more detail later, in the General Discussion). This would allow the stimuli A and B to become more dissimilar, thus reducing the generalization between them (i.e., resulting in a perceptual learning effect).

The present study investigates an implication of this analysis. If prolonged nonreinforced presentations of a stimulus result in an increase in its discriminability, then a perceptual learning effect equivalent to that observed when measuring habituation might also be evident when measuring LI. To our knowledge, there are no reported studies testing this prediction directly. However, some support for it is provided by a previous study carried out by our research group using the flavor-aversion learning procedure (Sanjuán, Alonso, \& Nelson, 2006, Experiment 2). In this experiment, four groups of rats were given conditioning trials in which a flavor compound $(\mathrm{AX})$ was paired with lithium chloride $(\mathrm{LiCl})$ induced illness. Groups differed, however, with respect to the treatment that they received prior to the conditioning phase. Three groups received different numbers of nonreinforced presentations of another flavor compound (BX) but were equated with respect to the amount of preexposure that they received to the common element of the two compounds (X). Thus, Group 8BX received eight presentations of BX; Group 4BX received four presentations of $\mathrm{BX}$ and four of $\mathrm{X}$, and Group 1BX received a single presentation of BX and seven presentations of X. Finally, a nonexposed control condition, Group $\mathrm{W}$, received water during the preexposure. It was found that Groups 1BX and 4BX acquired the aversion to AX more slowly than Group W. That is, a relatively short preexposure to $\mathrm{BX}$ apparently produced some generalization of LI from BX to AX. However, Group 8BX acquired the aversion to AX faster than Group 1BX and Group 4BX, and at a rate similar to that for Group W. That is, a relatively prolonged preexposure to $\mathrm{BX}$ did not produce any sign of generalization of LI from BX to AX. This pattern of results is compatible with the notion that extended preexposure to $\mathrm{BX}$ allowed this stimulus to become more dissimilar to $\mathrm{AX}$, thus reducing the generalization of LI between them. The present series of experiments were designed to extend the generality of this effect and to evaluate our interpretation of it as an instance of perceptual learning.

\section{Experiment 1}

According to our interpretation, equating the number of presentations of X (as Sanjuán et al., 2006, did) is not essential for obtaining the perceptual learning effect. If the critical factor in determining this effect is the amount of experience with the stimulus, then simply varying the number of presentations of BX should be enough to generate different degrees of generalization of LI between $\mathrm{BX}$ and $\mathrm{AX}$. The present experiment tested this implication. Four groups of rats (Groups $8 \mathrm{BX}, 4 \mathrm{BX}, 1 \mathrm{BX}$, and $\mathrm{W}$ ) initially received different numbers of nonreinforced presentations of BX (eight, four, one, or zero, respectively). All then received a conditioning and a test trial with AX. We expected to confirm that under these preexposure conditions, generalization of LI from $\mathrm{BX}$ to $\mathrm{AX}$ still decreases as preexposure to $\mathrm{BX}$ increases.

\section{Method}

\section{Subjects and apparatus}

The subjects were 32 experimentally naïve Wistar male rats with a mean ad-lib weight of $330 \mathrm{~g}$ at the start of the experiment. Animals were singly housed with continuous access to food in a room with a constant temperature $\left(23^{\circ} \mathrm{C}\right)$ and humidity (50\%) and a 12:12-h light:dark cycle, with light on at 08:00. Access to water was restricted as detailed below.

Solutions were administered, in the home cages, at room temperature through 50-ml plastic centrifuge tubes, fitted with a metal spout. The following flavored compound solutions were used: a compound consisting of $0.01-\mathrm{M}$ hydrochloric acid $(\mathrm{HCl})$ and $0.16-\mathrm{M}$ saline, and a compound of $0.01-\mathrm{M} \mathrm{HCl}$ and $0.33-\mathrm{M}$ sucrose (counterbalanced between AX and BX compounds). The unconditioned stimulus for the conditioning trials was an intraperitoneal injection of $\mathrm{LiCl}(0.3 \mathrm{M}$ at $10 \mathrm{ml} / \mathrm{kg})$.

\section{Procedure}

Water deprivation The water deprivation regime was initiated by removing the standard water bottles in the morning. On the next 4 days, access to water was restricted to two daily sessions of $30 \mathrm{~min}$, beginning at 13:00 (afternoon session) and 18:00 (evening session). Presenta- 
tion of fluids continued to be given at these times daily throughout the experiment. The experimental sessions were conducted in the afternoon session. In the evening session, all animals received water.

Preexposure to $B X$ At this point, the rats were randomly assigned to one of the four equal-sized experimental groups. During every afternoon session over the next 8 days, the animals received $30-\mathrm{min}$ access to $10 \mathrm{ml}$ of the corresponding solution. Animals in Group 8BX received eight presentations of $\mathrm{BX}$ on consecutive days; animals in Group 4BX received four presentations of BX on the last 4 days of preexposure, and four presentations of water on the initial 4 days; animals in Group 1BX received one presentation of $\mathrm{BX}$ on the last day of preexposure, and seven presentations of water on the initial 7 days; animals in Group W received water every day.

Conditioning and test with $A X$ A conditioning trial was given in the afternoon session the day after preexposure ended. It consisted of a 30-min presentation of $10 \mathrm{ml}$ of AX, followed immediately by an injection of $\mathrm{LiCl}$. The rats were given free access to water in the evening session. The next day was a recovery day, on which animals had unrestricted access to water for $30 \mathrm{~min}$ during both afternoon and evening sessions. After the recovery day, the rats were given a test trial that consisted of a 30-min presentation of $10 \mathrm{ml}$ of AX.

\section{Results}

The rats drank almost all of the fluid made available to them during each of the preexposure sessions. Figure 1 shows group means for consumption during the conditioning and the test trial. It is evident that the conditioning procedure was effective in establishing an aversion to AX, since consumption in all four groups had declined by the test trial. However, the rate at which that aversion was acquired differed among the groups. Groups 1BX and 4BX suppressed consumption of AX less readily than did Groups 8BX and W. A Group x Trial ANOVA confirmed all of these impressions, revealing main effects of group, $F$ $(3,28)=4.85$ (here and elsewhere, a significance level of $p<.05$ was adopted), and trial, $F(1,28)=463.07$, and a Group $\mathrm{x}$ Trial interaction, $F(3,28)=4.49$. A simple maineffects analysis of this interaction showed significant differences among the groups on the test trial, $F(3,28)=$ 4.91 , but not on the conditioning trial, $F(3,28)=1.21$. A further analysis using Duncan's multiple-range test revealed that on the test trial, Groups 1BX and 4BX differed from Groups $8 \mathrm{BX}$ and $\mathrm{W}$. The other pairwise comparisons yielded no significant differences. Our results thus confirm those found by Sanjuán et al.(2006; Experiment 2) and

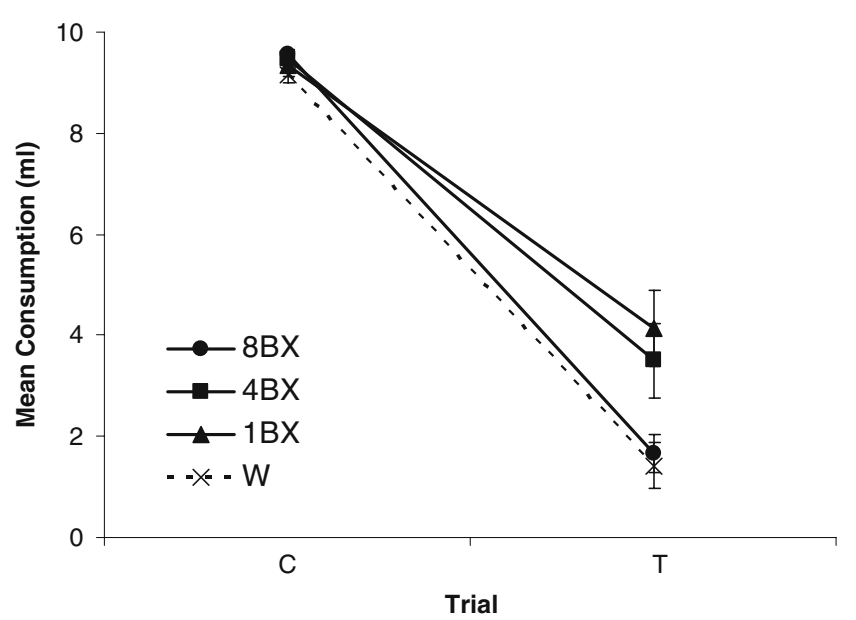

Fig. 1 Experiment 1: Mean scores for consumption of AX during the conditioning (C) and the test trial (T). Training conditions are illustrated in Table 1 and described in the text. Vertical bars represent the standard errors of the means (SEMs)

extend them to a more straightforward exposure procedure; pretraining consisting of one or four nonreinforced presentations of BX retarded acquisition of the aversion to $\mathrm{AX}$ on subsequent conditioning. However, there was no evidence of such retardation after eight nonreinforced presentations of BX. These results strengthen the view that a relatively extended preexposure to $\mathrm{BX}$ reduces in some way the similarity between $\mathrm{BX}$ and $\mathrm{AX}$, thus reducing the degree of generalization of LI between them.

\section{Experiment 2}

The hypothesis mentioned above obviously presumes that BX acquired a considerable amount of LI during preexposure. However, Experiment 1 does not allow this premise to be either confirmed or dismissed, since it did not include a standard LI condition, in which the same stimulus was both preexposed and conditioned. We addressed this issue in the present experiment (see Table 1). The design included three of the conditions used in Experiment 1: Group 8BX, Group $1 \mathrm{BX}$, and Group W. In addition, two further conditions were included in order to assess the ability of our procedure to generate an LI effect. Groups 8AX and 1AX received, respectively, eight exposures and one exposure to the to-beconditioned flavor AX. It is well-known that the magnitude of LI is an increasing function of the number of stimulus presentations (e.g., De la Casa \& Lubow, 1995; Lantz, 1973). On the basis of this evidence, we expected to observe more LI (less suppression of consumption of AX) in Group 8AX than in Group 1AX. Furthermore, in accordance with the results of Experiment 1 (and those of Sanjuán et al., 2006), we expected to observe more generalization of LI (less suppression of consumption of $\mathrm{AX}$ ) in Group 1BX than in Group 8BX. 
Table 1 Experimental designs

\begin{tabular}{lll}
\hline Group & Preexposure & Conditioning and Test \\
\hline Experiment 1 & & \\
$8 \mathrm{BX}$ & $8 \mathrm{BX}$ & $1 \mathrm{AX}+1 \mathrm{AX}$ \\
4BX & $4 \mathrm{~W}, 4 \mathrm{BX}$ & \\
1BX & $7 \mathrm{~W}, 1 \mathrm{BX}$ & \\
W & $8 \mathrm{~W}$ & \\
Experiment 2 & \\
$8 \mathrm{BX}$ & $8 \mathrm{BX}$ & \\
1BX & $7 \mathrm{~W}, 1 \mathrm{BX}+1 \mathrm{AX}$ \\
$8 \mathrm{AX}$ & $8 \mathrm{AX}$ & \\
1AX & $7 \mathrm{~W}, 1 \mathrm{AX}$ & \\
W & $8 \mathrm{~W}$ \\
Experiment 3 & \\
$8 \mathrm{AX}-8 \mathrm{BX}$ & $8 \mathrm{AX} / 8 \mathrm{BX}$ & \\
$8 \mathrm{AX}-4 \mathrm{BX}$ & $8 \mathrm{AX} / 4 \mathrm{BX} / 4 \mathrm{~W}$ & \\
$8 \mathrm{AX}$ & $8 \mathrm{AX} / 8 \mathrm{~W}$ & \\
W & $16 \mathrm{~W}+1 \mathrm{AX}$ \\
Experiment 4 & & \\
$8 \mathrm{BX}$ & $8 \mathrm{BX}$ \\
$4 \mathrm{BX}$ & $4 \mathrm{~W}, 4 \mathrm{BX}$ & \\
1BX & $7 \mathrm{~W}, 1 \mathrm{BX}$ & \\
W & $8 \mathrm{~W}$ \\
\hline
\end{tabular}

A, B, and X refer to flavors; + refers to the administration of $\mathrm{LiCl}$.

\section{Method}

\section{Subjects and apparatus}

The subjects were 40 experimentally naïve Wistar male rats with a mean ad-lib weight of $310 \mathrm{~g}$ at the start of the experiment. They were maintained in the same way and on the same deprivation schedule as those used in Experiment 1.

\section{Procedure}

The rats were randomly assigned to five equal-sized groups. The procedure for Groups $8 \mathrm{BX}, 1 \mathrm{BX}$, and $\mathrm{W}$ was identical to that described in Experiment 1. Groups 8AX and $1 \mathrm{AX}$ received treatment identical to that received by Groups $8 \mathrm{BX}$ and $1 \mathrm{BX}$, respectively, except that subjects received presentations of AX (rather than BX) during the preexposure phase. In other respects not specified here, the procedure was the same as that described in Experiment 1.

\section{Results}

The rats drank almost all of the fluid made available to them during each of the preexposure sessions. Figure 2 shows group means for consumption during the conditioning and the test trial. It is apparent that acquisition of suppression

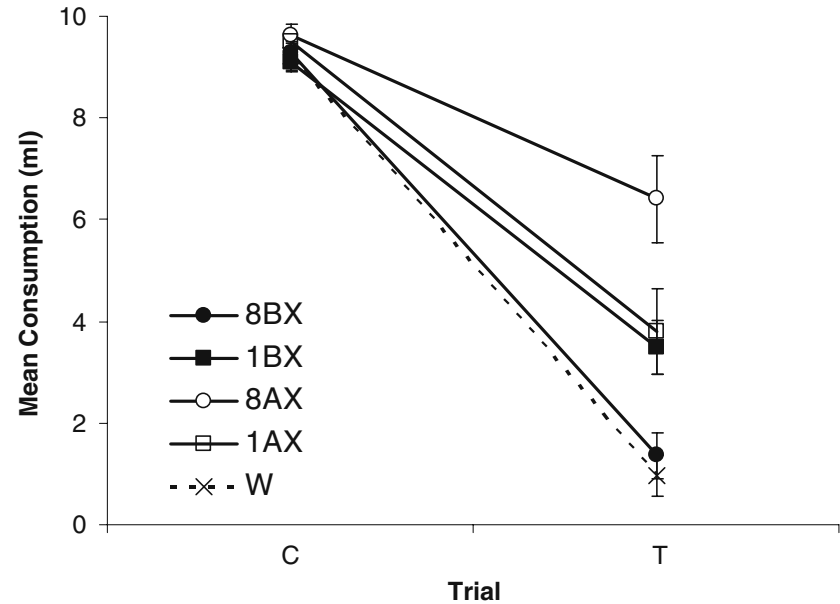

Fig. 2 Experiment 2: Mean scores for consumption of AX during the conditioning (C) and the test trial (T). Training conditions are illustrated in Table 1 and described in the text. Vertical bars represent the standard errors of the means (SEMs)

of consumption of $\mathrm{AX}$ was retarded in Group $8 \mathrm{AX}$ relative to the control Group W. Group 1AX showed a similar but much less marked retardation. This indicates that exposure and conditioning to the same stimulus (AX) resulted in an LI effect, which increased with the number of stimulus presentations (e.g., De la Casa \& Lubow, 1995). The opposite pattern was observed in subjects given exposure to BX. The suppression of consumption of AX was somewhat retarded in Group 1BX relative to Group W, but the performance of Group 8BX differed little from that control group. A Group $\mathrm{x}$ Trial ANOVA confirmed all of these impressions, revealing effects of group, $F(4,35)=11.44$, and trial, $F(1,35)=416.84$, and a Group x Trial interaction, $F(8,44)=9.27$. A simple maineffects analysis of this interaction showed significant differences among the groups on the test trial, $F(4,35)=$ 11.42 , but not on the conditioning trial, $F(4,35)<1$. A further analysis using Duncan's multiple-range test revealed that on the test trial, Group $8 \mathrm{AX}$ differed from each of the other groups, and Groups $1 \mathrm{AX}$ and $1 \mathrm{BX}$ differed from Groups $8 \mathrm{BX}$ and $\mathrm{W}$. The other pairwise comparisons yielded no significant differences.

These results confirm those of Experiment 1. An increase in the number of nonreinforced presentations of $\mathrm{BX}$ reduces generalization of LI from BX to AX. Importantly, the present experiment establishes that this happens in spite of the fact that extending the length of preexposure actually results in more LI to the preexposed stimulus.

\section{Experiment 3}

In the previous experiments, the test stimulus (AX) was novel when generalization of LI was assessed. Experiment 3 attempted to extend the generality of the basic experimental 
finding by examining the generalization of LI from BX to AX after preexposure to both stimuli (see Table 1). We included two of the conditions previously used in Experiment 2, Group 8AX and Group W, in order to assess the magnitude of the LI effect produced by eight nonreinforced presentations of AX. Two further groups were added to assess the role of generalization of LI from BX to AX. These groups also received eight presentations of $\mathrm{AX}$ during preexposure, but in addition they received eight or four presentations of BX (Groups 8AX-8BX and 8AX-4BX, respectively). The magnitude of the LI effect for these groups would be expected to be the sum of the LI resulting from the eight presentations of AX and the LI resulting from any generalization between BX and AX. In accordance with our previous results, we expected to observe some generalization of LI after four presentations of BX, but not after eight presentations. That is, we anticipated deeper retardation in the conditioning to $\mathrm{AX}$ (more $\mathrm{LI}$ ) in Group 8AX-4BX than in Groups 8AX-8BX and 8AX.

\section{Method}

\section{Subjects and apparatus}

The subjects were 32 experimentally naïve Wistar male rats with a mean ad-lib weight of $385 \mathrm{~g}$ at the start of the experiment. They were maintained in the same way and on the same deprivation schedule as those used in the previous experiments.

\section{Procedure}

Rats were randomly assigned to four equal-sized groups. The preexposure consisted of 16 days. Animals in Group $8 \mathrm{AX}-8 \mathrm{BX}$ received eight presentations of $\mathrm{AX}$ and eight presentations of $\mathrm{BX}$ on alternate days $(\mathrm{AX}, \mathrm{BX}, \mathrm{AX}$, $\mathrm{BX}, \ldots$ ). Group $8 \mathrm{AX}-4 \mathrm{BX}$ received alternate presentations of $\mathrm{AX}$ and water for the first 8 days of preexposure (AX, $\mathrm{W}, \mathrm{AX}, \mathrm{W}, \ldots)$ and alternate presentations of $\mathrm{AX}$ and $\mathrm{BX}$ on the following 8 days ( $\mathrm{AX}, \mathrm{BX}, \mathrm{AX}, \mathrm{BX}, \ldots)$. Group $8 \mathrm{AX}$ received alternate presentations of $\mathrm{AX}$ and water throughout the whole preexposure phase $(\mathrm{AX}, \mathrm{W}, \mathrm{AX}, \mathrm{W}, \ldots)$. Finally, Group W received water every day (W, W, W, $\mathrm{W}, \ldots$.). In other respects not specified here, the procedure was the same as that described in Experiments 1 and 2.

\section{Results}

The rats drank almost all of the fluid available during each of the preexposure sessions. Figure 3 shows group means for consumption during the conditioning and test trials. It is apparent that the suppression of consumption of AX was retarded in groups preexposed to this compound. This LI

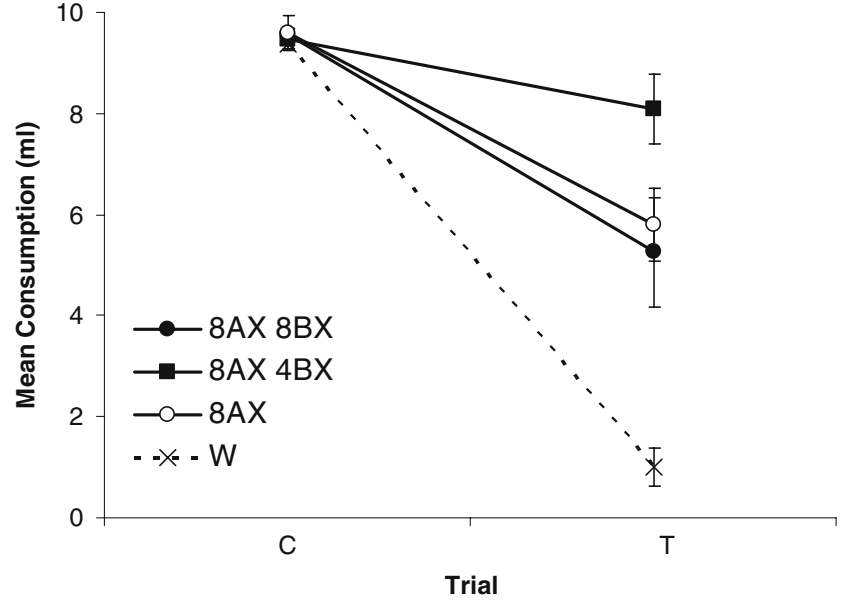

Fig. 3 Experiment 3: Mean scores for consumption of AX during the conditioning (C) and the test trial (T). Training conditions are illustrated in Table 1 and described in the text. Vertical bars represent the standard errors of the means (SEMs)

effect was more marked in Group $8 \mathrm{AX}-4 \mathrm{BX}$ than in Groups $8 \mathrm{AX}-8 \mathrm{BX}$ and $8 \mathrm{AX}$. This description of the data was supported by statistical analysis. A Group $\mathrm{x}$ Trial ANOVA revealed effects of group, $F(3,28)=11.85$, and trial, $F(1,28)=174.46$, and a Group $\mathrm{x}$ Trial interaction, $F$ $(3,28)=18.42$. A simple main-effects analysis of this interaction showed significant differences among the groups on the test trial, $F(3,28)=15.41$, but not on the conditioning trial, $F(3,28)<1$. A further analysis using Duncan's multiple-range test revealed that on the test trial, Group 8AX-4BX differed from each of the other groups, and Groups $8 \mathrm{AX}$ and $8 \mathrm{AX}-8 \mathrm{BX}$ differed from Group W. The other pairwise comparisons yielded no significant differences.

The present pattern of results is consistent with our analysis in terms of perceptual learning. It seems that the critical factor in determining the degree of generalization between $\mathrm{BX}$ and $\mathrm{AX}$ is the length of preexposure to (i.e., the amount of experience with) BX.

\section{Experiment 4}

Experiment 4 explored an interpretation of the effect that relies on the notion of "spontaneous configuring" (see, e.g., Razran, 1971). It has been suggested that when subjects are given a compound stimulus (for example, BX), they initially perceive and represent it in terms of individual elements (B and X). However, during the course of repeated presentations of the compound, subjects come gradually to form a configural representation of it (e.g., Bellingham \& Gillette, 1981; Forbes \& Holland, 1985; Gray \& Lethbridge, 1976). This proposal offers an 
explanation for our reducing-generalization effect. A relatively prolonged exposure to $\mathrm{BX}$ (eight presentations) could have been effective in establishing a configural representation of this compound. In that case, when the other compound, AX, was presented on conditioning, subjects' ability to perceive $\mathrm{X}$ as a constituent element of $\mathrm{BX}$ was reduced, and generalization from $\mathrm{BX}$ to $\mathrm{AX}$ thus failed to occur. However, with a shorter preexposure to BX (one or four presentations), the process of configuring would not have proceeded so far, and thus generalization still occurred to some extent.

It follows from this analysis that the presence of the A element during conditioning might not be essential to generating the reducing-generalization effect. If prolonged exposure to BX develops a configural cue, this compound should tend to be perceived as more dissimilar to AX, and also to its individual elements. (Actually, the term "spontaneous configuring" typically refers to an enhancement in the discrimination between the compound and its elements; "configuring" is said to be "spontaneous" because subjects receive no explicit training on this discrimination.) In the present experiment (see Table 1), we tested this implication. We included the four preexposure conditions used in Experiment 1: Groups 8BX, 4BX, 1BX, and W. After preexposure, all the animals received a conditioning and a test trial with $\mathrm{X}$. If prolonged exposure to $\mathrm{BX}$ brings into play a spontaneous configuring process, then generalization of LI from BX to $\mathrm{X}$ (i.e., consumption of $\mathrm{X}$ during the test trial) should be less in Group $8 \mathrm{BX}$ than in Groups 1BX and 4BX.

\section{Method}

\section{Subjects and apparatus}

The subjects were 32 experimentally naïve Wistar male rats with a mean ad-lib weight of $510 \mathrm{~g}$ at the start of the experiment. They were maintained in the same way and on the same deprivation schedule as those used in the previous experiments. The following flavored compound solutions were used: a compound consisting of $0.01-\mathrm{M} \mathrm{HCl}$ and $0.33-\mathrm{M}$ sucrose as $\mathrm{BX}$, and a $0.33-\mathrm{M}$ sucrose solution as $\mathrm{X}$.

\section{Procedure}

Rats were randomly assigned to four equal-sized groups: Groups $8 \mathrm{BX}, 4 \mathrm{BX}, 1 \mathrm{BX}$, and W. For all of these groups, the preexposure phase was identical to that of Experiment 1 The procedures for the conditioning and the test were also identical to those of previous experiments, except that the solution presented was $\mathrm{X}$ rather than $\mathrm{AX}$. In other respects not specified here, the procedure was the same as that described in the previous experiments.

\section{Results}

The rats drank almost all of the fluid available during each of the preexposure sessions. Figure 4 shows group means for consumption during the conditioning and the test trial. It is apparent that the rate at which the aversion was acquired differed among the groups. Suppression of consumption was retarded in Group 4BX with respect to the control Group W; Group 1BX showed a similar but less marked retardation; and finally, Group 8BX acquired the aversion to $\mathrm{X}$ at a rate more similar to that of control Group W. A Group $\mathrm{x}$ Trial ANOVA confirmed this description. The effect of group was close to being significant, $F(3,28)=2.86, p=$ .06 . The effect of trial, $F(1,28)=112.66$, and the Group $\mathrm{x}$ Trial interaction, $F(3,28)=7.62$, were significant. A simple main-effects analysis of this interaction showed significant differences among the groups on the test trial, $F(3,28)=$ 4.63 , but not on the conditioning trial, $F(3,28)<1$. A further analysis using Duncan's multiple-range test revealed that on the test trial Group 4BX differed from Groups 8BX and W, and Group 1BX differed from Group W. The other pairwise comparisons yielded no significant differences.

This pattern of results is congruent with the notion of spontaneous configuring. After short preexposure (one or four presentations), rats would have represented both AX and BX in terms of individual elements. This would have allowed effective processing of the $\mathrm{X}$ common element during both preexposure and conditioning, thus generating some degree of generalization of LI. However, after longer preexposure (eight presentations), animals would have tended to represent $\mathrm{BX}$ as a whole configuration, thus failing to notice that the $\mathrm{X}$ individual element presented on the AX conditioning trials was also a constituent part of the preexposed BX compound. Under these circumstances,

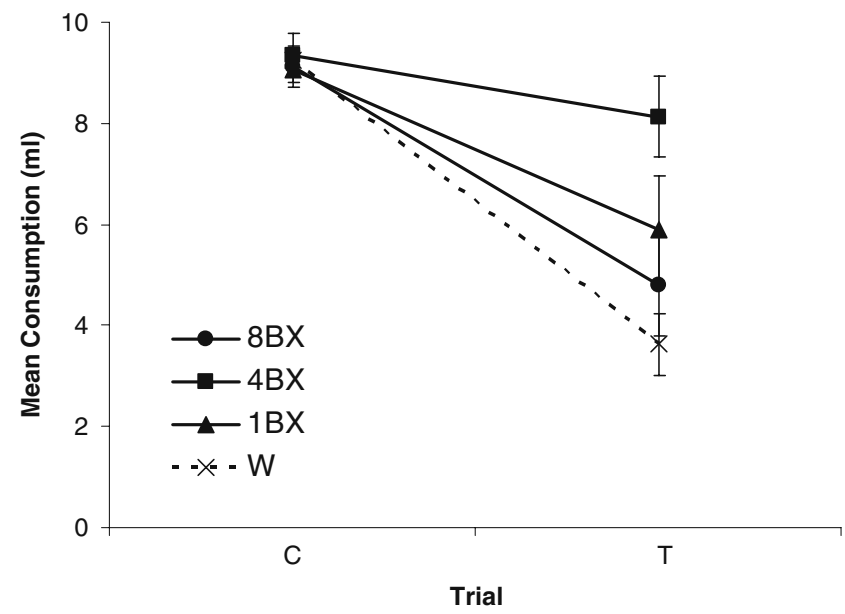

Fig. 4 Experiment 4: Mean scores for consumption of X during the conditioning (C) and the test trial $(\mathrm{T})$. Training conditions are illustrated in Table 1 and described in the text. Vertical bars represent the standard errors of the means (SEMs) 
generalization of LI between $\mathrm{BX}$ and $\mathrm{AX}$ is expected to be reduced, as was the case.

\section{General discussion}

The results of the experiments reported here can be summarized as follows. Generalization of LI between BX and $\mathrm{AX}$ was observed after a relatively short preexposure to $\mathrm{BX}$ (one or four presentations), but not after more prolonged preexposure to this compound (eight presentations); that is, increasing the length of preexposure to $\mathrm{BX}$ produced a generalization-reducing effect (Experiment 1). This effect occurred even though the longest stimulus preexposure (eight stimulus presentations) resulted in more LI than did shorter preexposure (one presentation) when the AX compound was both preexposed and conditioned (Experiment 2). A similar generalization-reducing effect was observed in a procedure in which both $\mathrm{BX}$ and $\mathrm{AX}$ were preexposed. Specifically, when the amounts of preexposure to $\mathrm{BX}$ and $\mathrm{AX}$ were equated (eight presentations of each), generalization of LI was less than when the preexposure to these stimuli was uneven (eight presentations of AX and four presentations of BX) (Experiment 3). Finally, a similar generalization-reducing effect was also observed when assessing generalization of LI from BX to $\mathrm{X}$ rather than from BX to AX (Experiment 4). Overall, these findings suggest that repeated exposure to BX enhanced its discriminability, preventing the LI endowed to this stimulus during preexposure from being generalized to other similar stimuli ( $\mathrm{AX}$ or $\mathrm{X}$ ). It remains to be explained how the preexposure turned BX into a stimulus more dissimilar from both $\mathrm{AX}$ and $\mathrm{X}$. That is, what mechanism reduced the perceptual effectiveness of the common elements of these stimuli? Next we will discuss three different accounts that might offer some answers to this question.

The first of these accounts relies on the phenomenon of habituation. It is widely accepted that nonreinforced preexposure to a stimulus acts to reduce its effective salience (see, e.g., Hall, 2003; McLaren \& Mackintosh, 2000, 2002). Therefore, there are grounds to think it likely that the longer the preexposure to BX, the less salient $\mathrm{X}$ will be, and the smaller will be the proportion of elements shared by BX and AX. This might explain the generalization-reducing effect found in Experiment 1, 2, and 3. However, the results from 4 do not support this account (or any other account based on the same principle; see McLaren \& Mackintosh, 2002, p.179). If the salience of $\mathrm{X}$ was most reduced by the longest preexposure to $\mathrm{BX}$, then conditioning with $\mathrm{X}$ should have progressed more slowly in this condition than after shorter preexposure, a result opposite to the one we found. The results reported by Sanjuán et al. (2006, Experiment 2) do not support an account in terms of the reduced salience of $\mathrm{X}$, either. In their experiment, a parallel generalization-reducing effect was found when the number of presentations of $\mathrm{X}$ during preexposure was equated between groups.

The second account (discussed by Hall, 1991, pp.58-66) is derived from the reasonable assumption that extended exposure to the training stimulus (BX) might allow the encoding of some of the features that escape attention when exposure is brief. Thus, if only a short exposure to BX is given, its representation will be lacking in detail. At the beginning of the conditioning phase, the conditioned stimulus ( $\mathrm{AX}$ or $\mathrm{X}$ ) will be represented imprecisely as well, since it is being presented for the first time. Under these circumstances, it seems likely that both the preexposed and the conditioned stimuli will be perceived as quite similar, and generalization will occur readily. On the other hand, if extended exposure to BX establishes all of its features, both common and unique, more firmly, its resulting representation will then be nearly exact. Under these circumstances, the conditioned stimulus ( $\mathrm{AX}$ or $\mathrm{X}$ ) will be perceived as more dissimilar to the very accurately represented trained stimulus (BX), and generalization will be weak.

The third account (also discussed by Hall, 1991, pp. 58-66) is that considered in Experiment 4, which is derived from the notion of spontaneous configuring. According to this suggestion, the way in which a compound stimulus is perceived changes with experience; more specifically, the compound is more likely to be perceived as a configuration (rather than as the sum of its constituent elements) after prolonged experience with it. According to this account, the failure to observe generalization of LI after the longest exposure to BX might be due to the emergence of a unique configural cue that enhances the discriminability of BX from both $\mathrm{AX}$ (Experiments 1, 2, and 3) and X (Experiment 4).

Our data seem to be equally well explained by the latter two accounts (encoding of stimulus features and spontaneous configuring). The extent to which the mechanisms described by these accounts contribute to the extended training effects remains to be specified in future experiments. What we may conclude so far, however, is that the present procedure of measuring generalization of LI provides a relatively novel way of evaluating extended training effects (and, potentially, a wider range of perceptual learning phenomena). Over the last few years, most of the research in perceptual learning with animals has made use of the generalization of conditioned aversions as an index of stimulus discriminability (e.g., Honey \& Hall, 1989; Mackintosh, Kaye, \& Bennett, 1991; Rodríguez \& Alonso, 2004; Symonds \& Hall, 1995). More specifically, 
rats' ability to discriminate between two flavors has been assessed by establishing an aversion to one of them, AX, and measuring the generalization of that aversion to the other stimulus, BX. Routinely, it has been found that preexposure to both $\mathrm{AX}$ and $\mathrm{BX}$ reduces the generalization between them. Our data have direct implications for one of the most accepted explanations offered for this perceptual learning effect: the differential LI mechanism proposed by McLaren, Kaye, and Mackintosh (1989; see also McLaren \& Mackintosh, 2000). This mechanism appeals to the fact that during preexposure to $\mathrm{AX}$ and $\mathrm{BX}$, their shared common features, $\mathrm{X}$, are presented twice as often as their unique features, A and B. Since it is well-known that LI is an increasing function of the number of stimulus presentations (see, e.g., De la Casa \& Lubow, 1995), it is assumed that this regime of preexposure results in more LI to X than to $\mathrm{A}$ or $\mathrm{B}$. Consequently, during subsequent conditioning with $\mathrm{AX}$, the aversion conditioned to $\mathrm{A}$ is expected to be stronger than that conditioned to $\mathrm{X}$, which would explain why generalization to $\mathrm{BX}$ is reduced. The generality of this mechanism is called into question by the results of our experiments, which show that when the preexposure to $\mathrm{BX}$ is relatively long, there is no transfer of $\mathrm{LI}$ from $\mathrm{BX}$ to $\mathrm{AX}$. In other words, preexposure to $\mathrm{X}$ in compound with $\mathrm{B}$ does not always guarantee transfer of LI when $\mathrm{X}$ is either conditioned in compound with $\mathrm{A}$ or conditioned in isolation. Clarifying this implication of our data will undoubtedly be of interest to future research.

\section{References}

Bellingham, W. P., \& Gillette, K. (1981). Spontaneous configuring to a tone-light compound using appetitive training. Learning and Motivation, 12, 420-434.

De la Casa, L. G., \& Lubow, R. E. (1995). Latent inhibition in conditioned taste aversion: The roles of stimulus frequency and duration, and amount of fluid ingested during preexposure. Neurobiology of Learning and Memory, 64, 125-132.

Forbes, D. T., \& Holland, P. C. (1985). Spontaneous configuring in conditioned flavor aversion. Journal of Experimental Psychology: Animal Behavior Processes, 11, 224-240.

Gillette, K., \& Bellingham, W. P. (1981). Loss of within-compound flavour association: Configural preconditioning. Experimental Animal Behavior, 1, 1-17.

Gray, T., \& Lethbridge, D. A. (1976). Configural conditioning in the CER: Loss of element strength after repeated reinforced compound CS trials. Learning and Motivation, 7, 532-539.

Hall, G. (1991). Perceptual and associative learning. Oxford: Oxford University Press, Clarendon Press.
Hall, G. (2003). Learned changes in the sensitivity of stimulus representations: Associative and nonassociative mechanisms. The Quarterly Journal of Experimental Psychology, 56B, 43-55.

Honey, R. C., \& Hall, G. (1989). Enhanced discriminability and reduced associability following flavor pre-exposure. Learning and Motivation, 20, 262-277.

Lantz, A. E. (1973). Effect of number of trials, interstimulus interval, and dishabituation during CS habituation on subsequent conditioning in a CER paradigm. Animal Learning \& Behavior, 1, 273-277.

Mackintosh, N. J. (1974). The psychology of animal learning. London: Academic Press.

Mackintosh, N. J., Kaye, H., \& Bennett, C. H. (1991). Perceptual learning in flavour aversion conditioning. The Quarterly Journal of Experimental Psychology, 43B, 297-322.

McLaren, I. P. L., Kaye, H., \& Mackintosh, N. J. (1989). An associative theory of the representation of stimuli: Applications to perceptual learning and latent inhibition. In R. G. M. Morris (Ed.), Parallel distributed processing: Implications for psychology and neurobiology (pp. 102-130). Oxford: Oxford University Press, Clarendon Press.

McLaren, I. P. L., \& Mackintosh, N. J. (2000). An elemental model of associative learning: I. Latent inhibition and perceptual learning. Animal Learning \& Behavior, 28, 211-246.

McLaren, I. P. L., \& Mackintosh, N. J. (2002). Associative learning and elemental representation: II. Generalization and discrimination. Animal Learning \& Behavior, 30, 177-200.

Razran, G. (1971). Mind in evolution. New York: Houghton Mifflin.

Rescorla, R. A. (1976). Stimulus generalization: Some predictions from a model of Pavlovian conditioning. Journal of Experimental Psychology: Animal Behavior Processes, 2, 88-96.

Rodríguez, G., \& Alonso, G. (2004). Perceptual learning in flavoraversion learning: Alternating and blocked exposure to a compound of flavors and to an element of that compound. Learning and Motivation, 35, 208-220.

Sanjuán, M. C., Alonso, G., \& Nelson, J. B. (2006). The contribution of latent inhibition to reduced generalization after pre-exposure to the test stimulus. Behavioural Processes, 71, 21-28.

Smith, B. D., \& Council, J. (1978). Overhabituation and dishabituation responses as a function of stimulus intensity and amount of overhabituation training. Psychophysiology, 15, 517-521.

Stephenson, D., \& Siddle, D. A. T. (1976). Effects of "below zero" habituation on the electrodermal orienting response to a test stimulus. Psychophysiology, 13, 10-15.

Symonds, M., \& Hall, G. (1995). Perceptual learning in flavor aversion learning: Roles of stimulus comparison and latent inhibition of common elements. Learning and Motivation, 26, 203-219.

Waters, W. F., \& MacDonald, D. G. (1974). Effects of "below zero" habituation on spontaneous recovery and dishabituation of the orienting response. Psychophysiology, 11, 548-558.

This research was supported by grants from the Spanish Ministerio de Educación y Ciencia (SEJ2005-02495), the Spanish Ministerio de Ciencia e Innovación (PSI2008-00412-PSIC), and the Gobierno Vasco (IT-276-07). The authors thank S. Giker for personal and technical support, and Byron Nelson for their very useful comments. 